\title{
FLUXOGRAMA PARA RECONHECIMENTO DE PADRÕES DE USO E COBERTURA DA TERRA EM TECIDO URBANO E PERIURBANO
}

\author{
FLOW CHART FOR PATTERN RECOGNITION AND \\ COVERAGE OF USE OF LAND IN AND PERIURBAN
}

\author{
Augusto Tomazzoni Lubenow* \\ Paulo Costa de Oliveira Filho*
}

\section{RESUMO}

Este trabalho teve como objetivo facilitar o reconhecimento de padrões de alvos urbanos e periurbanos, utilizando um fluxograma para interpretação de imagens de altíssima resolução. Foi utilizada uma ortoimagem colorida e fusionada do satélite Quickbird II de resolução espacial de 0,61 metros na identificação de elementos da composição urbana em uma cidade de pequeno porte. A partir da identificação dos alvos, eles foram comparados entre si e foi implementado um fluxograma para auxílio à decisão no processo de interpretação. O fluxograma implementado demonstrou ser eficiente na identificação dos alvos, e pode ser utilizado para fins educacionais ou de treinamento.

Palavras-chave: Sensoriamento remoto. Imagens de alta resolução. Elementos urbanos. Uso do solo urbano.

\begin{abstract}
The aim of this study was to facilitate the pattern recognition of urban and periurban targets areas through the use of a flowchart for the interpretation of very high resolution images. To this end a color orthoimage and fused Quickbird II satellite spatial resolution of 0.61 meters was used in the identification of elements of the urban composition in a small town. After the identification of the targets, they were compared; next a flowchart was used to aid the process of interpretation. The flowchart used has proven to be effective in identifying targets. It can also be used for educational or training purposes.
\end{abstract}

Keywords: Remote sensing. High resolution images. Urban elements. Urban land use.

\footnotetext{
*Universidade Estadual do Centro-Oeste, Setor de Ciências Agrárias e Ambientais, Departamento de Engenharia Ambiental, Irati, Paraná, E-mail: <guga-t@, hotmail.com>; <paulocostafh@irati.unicentro.br>.
} 


\section{Introdução}

Como a capacidade de resolução dos satélites tem aumentado, e as pesquisas das técnicas de obtenção, tratamento e interpretação evoluíram, o uso de imagens orbitais esta em franco crescimento para projetos de engenharia e planejamento urbano (PISANI, 1992). A gestão ambiental em prefeituras tem se beneficiado fortemente das ferramentas disponibilizadas pela tecnologia das imagens orbitais de alta resolução para a atualização da informação espacial, bem como para o planejamento de ações e a tomada de decisão.

O sensoriamento remoto é o uso de sensores para medir a quantidade de energia eletromagnética que emana de um objeto ou área geográfica à distância, e depois a extração de informação importante dos dados usando algoritmos baseados em matemática e estatística (FUSSELL et al., 1986). Conforme Novo (1989), sensor pode ser definido como qualquer equipamento capaz de transformar alguma forma de energia, convertê-la em sinal passível de ser registrado e apresentá-lo em forma adequada à extração de informações. A mesma autora afirma que para que sejam extraídas informações a partir de dados de sensoriamento remoto, é necessário conhecer o comportamento espectral dos alvos.

A determinação da natureza dos alvos pelos métodos de sensoriamento remoto é baseada no fato de que diferentes materiais são caracterizados por reflectâncias próprias, em cada banda do espectro. A utilização de imagens orbitais de sensores remotos vem se tornando muito comum na confecção de mapas de uso e cobertura do solo. Entretanto, as imagens disponíveis até meados da década de 1990 não possuíam resolução espacial suficiente para discriminar os alvos dentro do ambiente intra-urbano. Dessa forma, estudos detalhados sobre este ambiente só possuíam como fonte de dados de sensoriamento remoto as fotografias aéreas com alta resolução espacial (PINHO, et al., 2007). Um método utilizado para reconhecimento de padrões nas imagens é a interpretação visual e vetorização sobre tela seguida da classificação por associação de objetos poligonais. Atualmente, também têm sido utilizados aplicativos para a classificação supervisionada automática. Esses métodos exigem certa experiência com os parâmetros a serem definidos pelo intérprete. Quando a temática exige um detalhamento dos elementos da composição urbana e periurbana, as imagens de baixa e média resolução se tornam de difícil identificação visual dos alvos, pois o pixel representa uma área extensa, misturando vários alvos que teriam que ser separados, tornando difícil a interpretação. Os mesmos autores elaboraram redes semânticas específicas para alguns bairros da cidade de São José dos Campos, SP. A partir disso, foi desenvolvido um fluxograma capaz de abranger o maior número de elementos possíveis de uma composição urbana de uma cidade de médio porte. Este trabalho tem como objetivo analisar diversos alvos ou elementos da composição urbana em imagens digitais de altíssima resolução e desenvolver um fluxograma para o reconhecimento de padrões da paisagem urbana e periurbana na identificação dos elementos de uma cidade de pequeno porte.

Figura 1 - Delimitação da área de estudo.

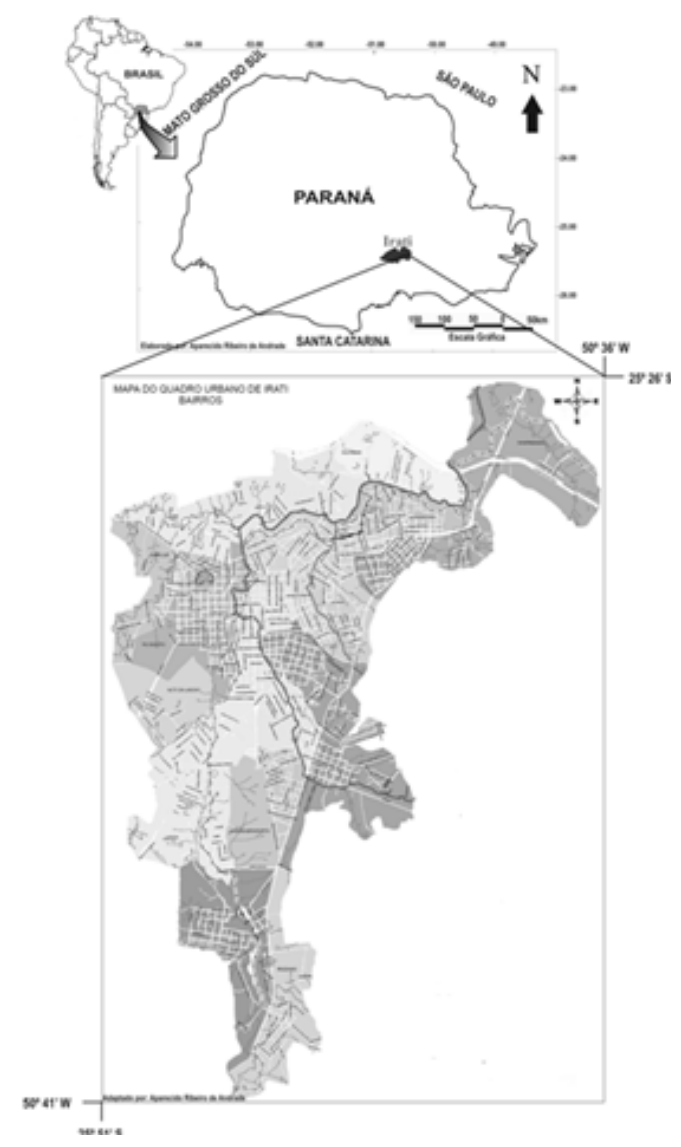




\section{Materiais e métodos}

\section{1 Área de estudo}

Irati encontra-se no paralelo $25^{\circ} 27^{\prime} 56^{\prime \prime}$ de latitude sul com interseção com o meridiano $50^{\circ}$ $37^{\prime} 51^{\prime \prime}$ de longitude oeste. Em linha reta, situa-se a $138 \mathrm{~km}$ de Curitiba, capital do estado, e a $1.105 \mathrm{~km}$ de Brasília, Distrito Federal. O município de Irati está localizado na zona fisiográfica de Irati, uma das onze em que o Paraná se divide. Encontra-se na sub-região dos pinhais do segundo planalto.

\subsection{Metodologia}

Para a realização do estudo, foi utilizado um segmento de imagem multiespectral fusionada de 61 cm de resolução, cedida pela Prefeitura Municipal de Irati, obtida pelo sensor Quickbird a bordo do satélite norte-americano Quickbird II. A imagem foi adquirida pelo Departamento de Planejamento da prefeitura no ano de 2009, e o segmento de imagem utilizado constitui-se de um recorte do quadro urbano. Foi utilizado o aplicativo SPRING versão 5.1.7.

Para os trabalhos de interpretação e para a elaboração do fluxograma foi utilizado o aplicativo Biazagi Modeler versão 2.0.0.2. O trabalho de campo correspondeu à etapa de checagem dos dados, no intuito de auxiliar no processo de interpretação da imagem. Procurou-se identificar, descrever e fotografar em campo, a partir de fotografias inclinadas coloridas normais obtidas do alto de um prédio, e posteriormente detalhar os elementos urbanos para associação com a imagem de satélite, como ilustrado nas Tabelas 1 e 2 . Foram fotografados os mesmos elementos interpretados e recortados na imagem de satélite e colocados lado a lado. Conforme o fluxograma da Figura 2, foram analisados alguns elementos básicos de interpretação, tais como: tonalidade, cor, forma, tamanho, textura, sombra, padrão e adjacências. Marques (2006) descreve alguns dos elementos de interpretação de imagens em estudos ambientais. Estes são aqui mencionados como base para os trabalhos de interpretação. A tonalidade é utilizada para interpretar fotografias ou imagens em tonalidades de cinza. A cor é um elemento utilizado na interpretação de imagens coloridas (em falsa cor), nas quais as variações da cena imageada são representadas por diferentes cores e nuances de cor. Em uma imagem colorida, a cor do objeto vai depender da quantidade de energia que ele refletir (na banda correspondente à imagem), da mistura entre as cores (processo aditivo), e da cor que for associada às bandas originais. A forma está relacionada com as feições dos elementos terrestres e é um dos fatores mais importantes na identificação de objetos, feições ou superfícies. De modo geral, formas irregulares são indicadoras de objetos naturais (matas, lagos, feições de relevo, pântanos etc.), enquanto formas regulares indicam objetos artificiais ou culturais, construídos pelo homem (indústrias, aeroportos, áreas de reflorestamento, áreas agrícolas, arborização de ruas etc.). $\mathrm{O}$ tamanho é o elemento que está relacionado com a superfície ou dimensões de volume de um determinado componente. O tamanho é função da resolução da imagem, e relativo aos objetos presentes na mesma. Em função do tamanho, pode-se distinguir uma residência de uma indústria ou supermercado. A textura é a frequência de mudança da tonalidade dentro de uma imagem. Esta se refere ao aspecto liso (e uniforme) ou rugoso dos objetos em uma imagem. A Sombra geralmente permite interpretar a forma ou o contorno dos objetos propiciando uma visão do perfil do objeto, facilitando seu reconhecimento. A sombra representada em uma imagem, assim como pode auxiliar na identificação de alguns objetos como pontes, chaminés, postes, árvores e feições de relevo, podem ocultar a visualização dos objetos por ela encobertos. Os padrões podem ajudar na identificação de objetos, uma vez que ele se refere ao arranjo espacial ou à organização desses objetos em uma superfície. E por último elemento de interpretação é a adjacência que na interpretação, às vezes, só é possível através de uma associação de evidências, pois muitos objetos nada dizem separadamente, porém se eles forem associados com outros que os cercam (áreas adjacentes), pode-se obter informações complementares. A observação dos detalhes circunvizinhos é o meio mais fácil de identificação de diversos objetos, pois cada um deles possui indícios que lhe são peculiares, por exemplo: uma construção grande com áreas interiores e uma quadra ou pista para prática de atividades físicas nos leva a crer que se trata de uma escola ou algo similar. 


\section{Resultados e discussão}

Foram diversos os elementos da composição urbana identificados e descritos nas Tabelas 1 e 2 . A Tabela 1 apresenta uma comparação entre diferentes tipos de cobertura urbana no segmento de composição colorida da imagem e respectivamente em fotografias aéreas inclinadas, com colorido normal de pequeno formato, obtidas do topo de um prédio. Elas evidenciam os mesmos alvos identificados nas imagens orbitais.

Tabela 1 - Comparação entre tipos de cobertura urbana

(continua)

\begin{tabular}{|c|c|c|c|}
\hline Classe & $\begin{array}{l}\text { Imagens } \\
\text { Quickbird }\end{array}$ & $\begin{array}{l}\text { Fotografias Inclinadas } \\
\text { Colorido Normal }\end{array}$ & Descrição \\
\hline Organizada & & & $\begin{array}{c}\text { Caracterizada com vegetação plantada em } \\
\text { logradouros que acompanham o sentido das } \\
\text { ruas. }\end{array}$ \\
\hline $\begin{array}{c}\text { Não } \\
\text { Organizada }\end{array}$ & & & $\begin{array}{l}\text { Encontrada dentro de lotes e parques onde } \\
\text { sua expansão foi de forma natural sem } \\
\text { restrição de espaço. }\end{array}$ \\
\hline $\begin{array}{l}\text { Vegetação } \\
\text { Rasteira }\end{array}$ & & & $\begin{array}{l}\text { Lotes vazios, ou frente de casas que possuem } \\
\text { gramínea como cobertura de solo. }\end{array}$ \\
\hline Sombra & & & $\begin{array}{l}\text { Imagem de baixo brilho que impossibilita } \\
\text { a identificação de elementos. Pode ser por } \\
\text { cobertura de nuvens, ou sombra de objetos } \\
\text { como árvores ou prédios. }\end{array}$ \\
\hline $\begin{array}{l}\text { Objeto de Alto } \\
\text { Brilho }\end{array}$ & & & $\begin{array}{l}\text { Imagem que sua refletância possui um alto } \\
\text { valor de reflectância impossibilitando a } \\
\text { identificação do mesmo. }\end{array}$ \\
\hline Cerâmica Escura & & & $\begin{array}{l}\text { São cerâmicas que alteram seu comportamento } \\
\text { espectral devido à impregnância de sujeira } \\
\text { ou até mesmo pela degradação da camada } \\
\text { de brilho por intemperismos. Apresentam } \\
\text { formatos geométricos de fácil percepção. }\end{array}$ \\
\hline Solo Escuro & & & $\begin{array}{l}\text { São os solos que apresentam maior teor de } \\
\text { matéria orgânica e umidade, ou solos que } \\
\text { possuem alguma mistura com brita para } \\
\text { melhorar o transporte nestes locais, dando um } \\
\text { aspecto de ser um solo escuro. }\end{array}$ \\
\hline
\end{tabular}


(conclusão)

\begin{tabular}{|c|c|c|c|}
\hline Classe & $\begin{array}{l}\text { Imagens } \\
\text { Quickbird }\end{array}$ & $\begin{array}{l}\text { Fotografias Inclinadas } \\
\text { Colorido Normal }\end{array}$ & Descrição \\
\hline Cerâmica Clara & & & $\begin{array}{l}\text { Constituídos de cerâmicas novas ou que } \\
\text { passaram por um processo de manutenção } \\
\text { retirando material que fica incrustado. } \\
\text { Apresentam formatos geométricos de fácil } \\
\text { identificação. }\end{array}$ \\
\hline Solo Claro & & & $\begin{array}{l}\text { O solo predominante da região apresenta em } \\
\text { sua composição altos valores de reflectância, } \\
\text { característica desse tipo de solo que é o } \\
\text { podzólico vermelho amarelo. }\end{array}$ \\
\hline Piscina & & & $\begin{array}{c}\text { Caracterizado por cores de azul ou verde. A } \\
\text { piscina apresenta raias de natação e formatos } \\
\text { retangulares. }\end{array}$ \\
\hline $\begin{array}{l}\text { Concreto/ } \\
\text { Cobertura Média }\end{array}$ & & & $\begin{array}{l}\text { É identificado como superfície que foi usado } \\
\text { cimento, pois o cimento apresenta uma cor } \\
\text { mais clara que o concreto e o asfalto. }\end{array}$ \\
\hline $\begin{array}{l}\text { Brita/ } \\
\text { Pedregulhos }\end{array}$ & & & $\begin{array}{l}\text { É encontrado em pátios de fábricas, casa, } \\
\text { estacionamentos. Apresenta uma cor escura. }\end{array}$ \\
\hline $\begin{array}{l}\text { Cobertura } \\
\text { Metálica }\end{array}$ & & & $\begin{array}{l}\text { Apresenta brilho característico e seu formato } \\
\text { possui uma forma geométrica fácil de ser } \\
\text { reconhecida. }\end{array}$ \\
\hline Asfalto & & & $\begin{array}{l}\text { A presença de objetos com formato de regulares } \\
\text { permite sua identificação como também } \\
\text { pela presença de faixas de sinalização e a } \\
\text { continuidade desses elementos por toda a área. }\end{array}$ \\
\hline $\begin{array}{l}\text { Concreto/ } \\
\text { Cobertura Escura } \\
\text { De Fato }\end{array}$ & & & $\begin{array}{l}\text { Lugares que possuem concreto com certo } \\
\text { tempo, onde as ações do tempo deixam o mais } \\
\text { escuro. Com lajes de prédios e casas. }\end{array}$ \\
\hline $\begin{array}{l}\text { Superfície De } \\
\text { Pedra Regular }\end{array}$ & & & $\begin{array}{l}\text { Possui as mesmas características do asfalto, } \\
\text { porém as tonalidades possuem uma variância, e } \\
\text { não têm faixas de sinalização pintadas na via. }\end{array}$ \\
\hline
\end{tabular}

Os padrões típicos são caracterizados pelo agrupamento de elementos. 
Tabela 2 - Padrões Típicos de elementos urbanos e periurbanos

\begin{tabular}{|c|c|c|}
\hline Classe & Imagens Quickbird & Descrição \\
\hline Cemitério & Tog & $\begin{array}{l}\text { A organização de elementos com uma grande proximidade e de tamanho } \\
\text { inferior a residências. }\end{array}$ \\
\hline Estacionamiento & & $\begin{array}{c}\text { Grandes áreas, com presença de faixa organizando a parada dos carros; } \\
\text { há presença de carros. }\end{array}$ \\
\hline Silo & & Com cores próximas do cinza e formas geométricas cilíndricas. \\
\hline $\begin{array}{l}\text { Complexo } \\
\text { Industrial }\end{array}$ & & $\begin{array}{l}\text { Presença de vários barracões; Cercas determinando uma grande área; } \\
\text { Presença de matérias prima no pátio, chaminés, lagoas de tratamento, } \\
\text { estacionamento de caminhões. }\end{array}$ \\
\hline Central Elétrica & & $\begin{array}{l}\text { São áreas que têm cobertura escura no fundo, e apresentam postes e } \\
\text { linhas de transmissão muito próximos um do outro. }\end{array}$ \\
\hline Escolas & & $\begin{array}{c}\text { São caracterizadas por grandes instalações, que apresentam cobertura } \\
\text { com cerâmica; Presença de pátio para recreação; Algumas apresentam } \\
\text { quadras para atividade física sem e com cobertura. }\end{array}$ \\
\hline $\begin{array}{l}\text { Complexo } \\
\text { Esportivo }\end{array}$ & & $\begin{array}{l}\text { Formato geométrico retangular e a presença de linhas demarcando os } \\
\qquad \text { limites do jogo. }\end{array}$ \\
\hline $\begin{array}{l}\text { Estação } \\
\text { Ferroviária/ } \\
\text { Linha Férrea }\end{array}$ & & $\begin{array}{l}\text { Apesar de imagens de resolução submétrica não identificarem os trilhos, } \\
\text { elas mostram a presença de linhas paralelas e a existência vagões que são } \\
\text { identificados pelo formato e a distância entre si. }\end{array}$ \\
\hline Lagoas & & $\begin{array}{l}\text { Não apresentam uma forma geométrica regular; A cor pode ser tanto } \\
\text { azul ou verde, porém em casos de tanques de criação de peixe, a cor se } \\
\text { aproxima do marrom claro; Presença de árvores ao seu redor. }\end{array}$ \\
\hline
\end{tabular}


A seguir, a Figura 02 apresenta o fluxograma de reconhecimento de cobertura urbana elaborado. Com base nele, foi possível elaborar um exercício de interpretação que pode ser utilizado como forma de treinamento para imagens com resolução semelhante.

Figura 02 - Fluxograma de reconhecimento de cobertura urbana.

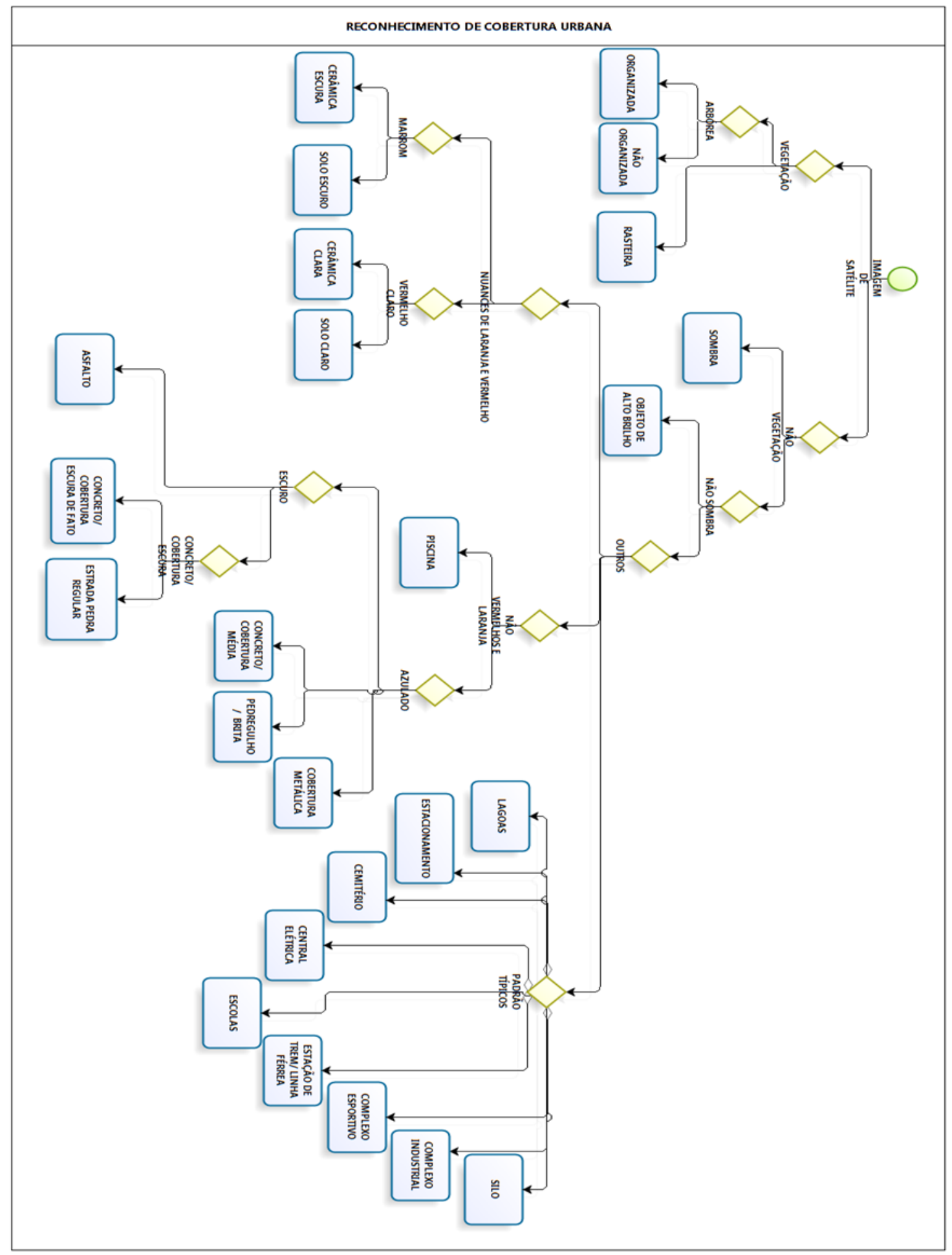




\section{Conclusões}

- O fluxograma desenvolvido pode ser utilizado quando não se tem experiência na interpretação de imagens de resolução semelhante e como forma de treinamento e uso educacional;

- Para trabalhos de interpretação de qualquer elemento urbano que possui um padrão típico, o fluxograma pode oferecer auxílio e reduzir o tempo de interpretação.

\section{Agradecimentos}

Os autores agradecem à Prefeitura Municipal de Irati, pela cessão das imagens de satélite, fundamentais a este estudo, e ao Conselho Nacional de Desenvolvimento Científico e Tecnológico (CNPq) pela bolsa de iniciação científica cedida ao aluno Augusto Tomazzoni Lubenow.

\section{Referências}

ESTEVAM, E. A. Classificação de áreas de favelas a partir de imagens IKONOS: viabilidade de uso de uma abordagem orientada a objetos. Presidente Prudente: UNESP, 127 f. (Dissertação de Mestrado) - Programa de Pós-Graduação em Ciências cartográficas, Universidade Estadual de São Paulo, Campus de Presidente Prudente, 2006.

FUSSEL, J., RUNDQUIST, D.; Harrington, J. A. On defining remote sensing. Photogrammetric Engineering \& Remote Sensing, v.52, n.9, p.1507-1511, 1986.

MARQUES, W. R. Interpretação de Imagens de Satélites em Estudos Ambientais. Ambiência - Revista do Centro de Ciências Agrárias e Ambientais, Guarapuava, v. 2, n. 2, p. 291-299, jul/dez. 2006.

NOVO, E. M. L. Sensoriamento remoto: princípios e aplicações. 2.ed. São Paulo, Edgard Blücher, 1989.

PISANI, M. A. Sensoriamento remoto via orbital aplicado a estudos urbanos. São Paulo: EPUSP. (Boletim Técnico da Escola Politécnica da USP, Departamento de Engenharia de construção civil). 1992.14 p.

PINHO, C. M. D. et al. Influência de Diferentes padrões de ocupação do solo urbano na qualidade de mapeamentos de cobertura do solo em imagens de alta resolução espacial: estudo de caso de São Jose dos Campos(SP) In: BLASCHEKE, T., KUX, H. (Org.). Sensoriamento remoto e SIG avançados. São Paulo: Oficinas de Textos, 2007. p.198-226.
SILVA, E. A. Extração de feições cartográficas de imagens multiespectrais fundidas. (Tese de doutorado em engenharia) - Escola Politécnica da Universidade de São Paulo. USP, São Paulo, 1995. 109p. 